\title{
Temperature-induced metal-insulator transition in a non-symmetric Hubbard model at half-filling
}

\author{
L.Didukh, V.Hankevych \\ Ternopil State Technical University, Department of Physics, \\ 56 Rus'ka Str., 282001 Ternopil, Ukraine
}

Received June 8, 1998, in final form June 22, 1998

In the present paper metal-to-insulator transition with the increase of temperature is studied in a narrow-band model with non-equivalent Hubbard subbands at half-filling. It is shown that the results obtained in the considered model are essentially distinct from those obtained in the Hubbard model. The results are applied to the interpretation of some experimental data.

Key words: metal-insulator transition, narrow energy bands, non-equivalent Hubbard subbands

PACS: $71.30 .+h, 71.28 .+d, 71.10 . F d, 71.27 .+a$

\section{Introduction}

It is known that the electron-hole symmetry is peculiar to the Hubbard model [1]. One of the manifestations of this symmetry is the equivalence of the lower and upper Hubbard bands. It is the result of the equality of hopping integrals describing both "translational" hopping of holes and doubly occupied sites (doublons) and the processes of their paired creation and destruction. Equality of noted hopping integrals is caused by neglecting the matrix elements of electron-electron interaction

$$
J(i k j k)=\iint \phi^{*}\left(\mathbf{r}-\mathbf{R}_{\mathbf{i}}\right) \phi\left(\mathbf{r}-\mathbf{R}_{\mathbf{j}}\right) \frac{e^{2}}{\left|\mathbf{r}-\mathbf{r}^{\prime}\right|}\left|\phi\left(\mathbf{r}^{\prime}-\mathbf{R}_{\mathbf{k}}\right)\right|^{2} \mathbf{d r d} \mathbf{r}^{\prime},
$$

in the Hamiltonian of model (the matrix elements (1.1) describe hopping of electrons between $i$ and $j$ lattice sites; $\phi$-function is the Wannier function).

However, the theoretical analysis, on the one hand, and the available experimental data, on the other hand, indicate the fact that the Hubbard model generalization is of a principle necessity taking into account the correlated hopping (1.1) [2-6]. In such a model, hopping integrals describing "translational" hopping of holes and doublons are different. These hopping integrals also differ from the hopping integral 
which is connected with the processes of paired creation and destruction of holes and doublons. Consequently, the lower and upper Hubbard bands are non-equivalent (non-symmetric). In recent years, similar models have been studied intensively [714].

An important puzzle arising in studying these models is a metal-insulator transition problem which is one of the most essential in narrow-band physics [15-17]. In this connection special interest is challenged by the observable metal-to-insulator transitions in some narrow-band materials with the increase of temperature (see, for example [17-22]).

Based on the approach proposed in the papers [5,23] we have studied metalinsulator transition in a model of narrow-band material with non-equivalent Hubbard subbands (the so-called "non-symmetric Hubbard model") at half-filling and zero temperature in the paper [24]. The present paper is devoted to a further study of metal-insulator transition in a model with non-equivalent Hubbard subbands, in particular, to the study of temperature-induced metal-to-insulator transition.

\section{Results}

We start from the following natural generalization of the Hubbard model [1] at half-filling including correlated hopping (1.1) [4,5]

$$
\begin{aligned}
H= & -\mu \sum_{i \sigma} a_{i \sigma}^{+} a_{i \sigma}+\left(t_{0}+T_{1}\right) \sum_{i j \sigma}^{\prime} a_{i \sigma}^{+} a_{j \sigma}+T_{2} \sum_{i j \sigma}^{\prime}\left(a_{i \sigma}^{+} a_{j \sigma} n_{i \bar{\sigma}}+\text { h.c. }\right) \\
& +U \sum_{i} n_{i \uparrow} n_{i \downarrow},
\end{aligned}
$$

with $i, j$ nearest-neighbours sites, $\mu$ is the chemical potential, $a_{i \sigma}^{+},\left(a_{i \sigma}\right)$ is the creation (destruction) operator of an electron of spin $\sigma(\sigma=\uparrow, \downarrow)$ on $i$-site $(\bar{\sigma}$ denotes spin projection which is opposite to $\sigma), n_{i \sigma}=a_{i \sigma}^{+} a_{i \sigma}$ is the number operator of electrons of spin $\sigma$ on $i$-site, $U$ is the intra-atomic Coulomb repulsion, $t_{0}, T_{1}, T_{2}$ are the integrals of electron hopping between the nearest neighbours,

$$
T_{1}=\sum_{k \neq i, j} J(i k j k), \quad T_{2}=J(i i i j)
$$

the primes at the sums in Hamiltonian (2.1) signify that $i \neq j$.

Using a generalized mean-field approximation $[5,23]$ in Green function method we obtain for a paramagnetic state the single-particle energy spectrum as

$$
\begin{aligned}
& E_{1,2}(\mathbf{k})=-\mu+\frac{(1-2 d)\left(t_{\mathbf{k}}+\tilde{t}_{\mathbf{k}}\right)+U}{2} \mp \frac{1}{2} F_{\mathbf{k}}, \\
& F_{\mathbf{k}}=\sqrt{\left[B\left(t_{\mathbf{k}}-\tilde{t}_{\mathbf{k}}\right)-U\right]^{2}+\left(4 d t_{\mathbf{k}}^{\prime}\right)^{2}}, \quad B=1-2 d+4 d^{2},
\end{aligned}
$$

where $d$ is the concentration of polar states (holes or doublons), $t_{\mathbf{k}}, \tilde{t}_{\mathbf{k}}, t_{\mathbf{k}}^{\prime}$ are the Fourier transforms of the respective nearest-neighbour hopping integrals $t=$ 
$t_{0}+T_{1}, \tilde{t}=t+2 T_{2}, t^{\prime}=t+T_{2} ; t$ and $\tilde{t}$ are terms describing hopping of quasiparticles within the lower and upper Hubbard bands (hopping of holes and doublons) respectively, $t^{\prime}$ describes quasiparticle hopping between hole and doublon bands (the processes of paired creation and destruction of holes and doublons).

The peculiarity of single-particle energy spectrum (2.2) is the dependence on temperature ( $d$ is a function of temperature). Thus, the proposed approach makes it possible to study temperature-induced metal-insulator transition.

The energy gap width (difference of energies between bottom of the upper and top of the lower Hubbard bands) is

$$
\begin{aligned}
\Delta E & =-(1-2 d)(w+\tilde{w})+\frac{1}{2}\left(Q_{1}+Q_{2}\right), \\
Q_{1} & =\sqrt{[B(w-\tilde{w})-U]^{2}+\left(4 d z t^{\prime}\right)^{2}}, \\
Q_{2} & =\sqrt{[B(w-\tilde{w})+U]^{2}+\left(4 d z t^{\prime}\right)^{2}},
\end{aligned}
$$

where $w=z|t|, \tilde{w}=z|\tilde{t}|$ ( $z$ is the number of the nearest neighbours to the site).

The concentration of polar states (obtained using the Green function $\left.\left\langle\left\langle a_{i \sigma} n_{i \bar{\sigma}} \mid a_{j \sigma}^{+}\right\rangle\right\rangle\right)$is $[24]$

$$
\begin{aligned}
& d=\frac{1}{4 w} \int_{-w}^{w}\left[\frac{C_{\varepsilon}}{\exp \frac{E_{1}(\varepsilon)}{k_{\mathrm{B}} T}+1}+\frac{D_{\varepsilon}}{\exp \frac{E_{2}(\varepsilon)}{k_{\mathrm{B}} T}+1}\right] \mathrm{d} \varepsilon \\
& C_{\varepsilon}=\frac{1}{2}-\frac{U}{2 F_{\varepsilon}}-\frac{B \varepsilon}{2 F_{\varepsilon}}\left(\frac{\tilde{t}}{t}-1\right), \quad D_{\varepsilon}=\frac{1}{2}+\frac{U}{2 F_{\varepsilon}}+\frac{B \varepsilon}{2 F_{\varepsilon}}\left(\frac{\tilde{t}}{t}-1\right),
\end{aligned}
$$

and chemical potential of narrow-band model with non-equivalent Hubbard subbands is given by the equation

$$
\int_{-w}^{w}\left[\frac{1}{\exp \frac{-E_{2}(\varepsilon)}{k_{\mathrm{B}} T}+1}-\frac{1}{\exp \frac{E_{1}(\varepsilon)}{k_{\mathrm{B}} T}+1}\right] \mathrm{d} \varepsilon=0,
$$

$E_{1,2}(\varepsilon), F_{\varepsilon}$ are obtained from respective formulae $(2.2),(2.3)$ for $E_{1,2}(\mathbf{k}), F_{\mathbf{k}}$ by substitution of $t_{\mathbf{k}} \rightarrow \varepsilon, \tilde{t}_{\mathbf{k}} \rightarrow(\tilde{t} / t) \varepsilon, t_{\mathbf{k}}^{\prime} \rightarrow\left(t^{\prime} / t\right) \varepsilon$. Here we have used the rectangular density of states.

\section{Discussions and conclusions}

The temperature dependence of chemical potential of a narrow-band model with non-equivalent Hubbard subbands obtained from equation (2.8) is plotted in figure 1 . One can see that in the considered model chemical potential is essentially dependent not only on the parameters $w$ and $\tilde{w}$ but also on temperature (in contrast to the Hubbard model where $\mu=U / 2$ ), and moreover, the chemical potential rapidly increases with the decrease of temperature depending on the parameters of 


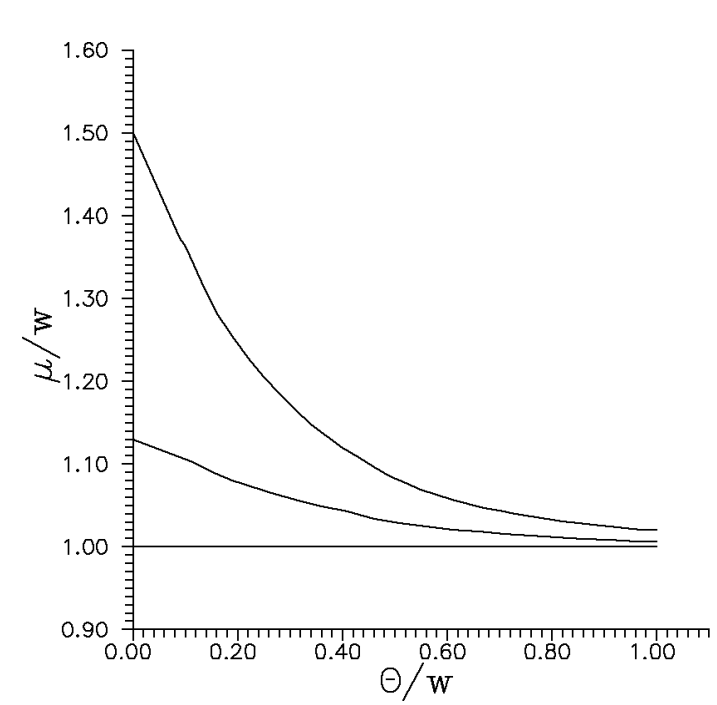

Figure 1. The temperature dependence $\left(\theta=k_{B} T\right)$ of chemical potential $\mu$ for $U / 2 w=1$ : the upper curve corresponds to $\tau_{1}=\tau_{2}=0.3$; the lower curve $-\tau_{1}=\tau_{2}=0.1$; the straight line corresponds to values of chemical potential in the Hubbard model $\left(\tau_{1}=\tau_{2}=0\right)$.

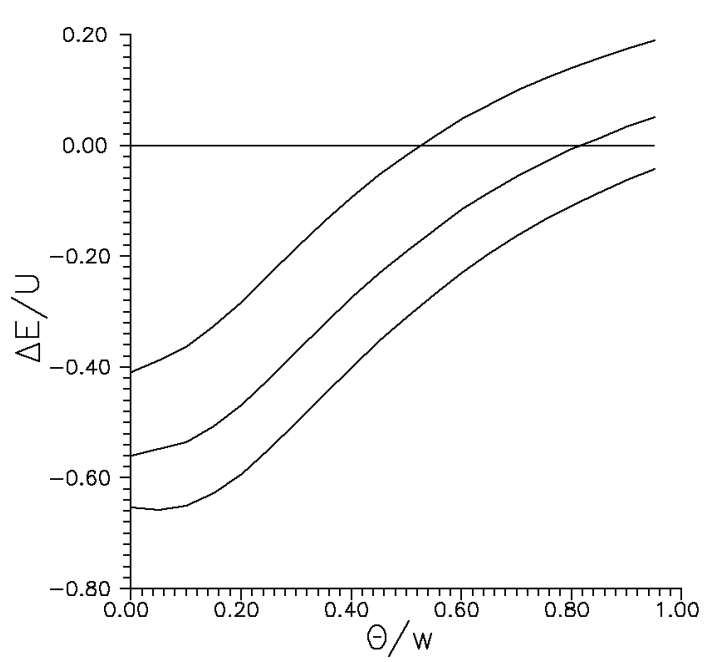

Figure 2. The dependence of energy gap on temperature at $U / w=0.9$. The upper curve corresponds to $\tau_{1}=$ $\tau_{2}=0.2$, the middle curve $-\tau_{1}=$ $\tau_{2}=0.1$, the lower curve $-\tau_{1}=\tau_{2}=$ 0 (the Hubbard model).

non-equivalence of Hubbard subbands $\tau_{1}, \tau_{2}$. In a high temperature region in the proposed model, the chemical potential tends to $U / 2$ with the increase of temperature; really, at $T \rightarrow \infty$ the probabilities of an electron finding within the lower and upper Hubbard bands (independent of their bandwidth ratio) are equal.

At a given $U, w, \tilde{w}, t^{\prime}$ (constant exterior pressure), the concentration of polar states (2.7) increases with the increase of temperature. It leads to the fact that the system can undergo transition from the state with $\Delta E \leqslant 0$ to the state with $\Delta E>0$, i.e. metal-to-insulator transition can occur. In this case the results obtained in the Hubbard model and those obtained in non-symmetric Hubbard model can be essentially different (figure 2 illustrates it). Let us take for example $U / w=0.9$. One can see that at $T=0 \mathrm{~K}$ the energy gap width in both models is $\Delta E<0$ (a metallic state). With the increase of temperature, metal-to-insulator transition does not occur in the Hubbard model, in a non-symmetric model the values of parameters $\tau_{1}, \tau_{2}$ exist at which metal-to-insulator transition occurs.

In case the metal-to-insulator transition occurs in both models from figure 2 one can see that at given values of $U / w$ in a model with non-equivalent Hubbard subbands, metal-to-insulator transition occurs at a smaller temperature than in the Hubbard model. So, for example, for $w_{0}=z\left|t_{0}\right| \approx 1.05 \mathrm{eV}$ (such bandwidth of $\mathrm{NiS}_{2}$ was estimated in the paper [19]) in the considered model in a paramagnetic state metal-to-insulator transition occurs at $T \approx 280 \mathrm{~K}$ for $U / w_{0}=1.94$ and $\tau_{1}=\tau_{2}=$ 0.01 (observable the transition temperature of $\mathrm{NiS}_{2}$ is $T \sim 280 \mathrm{~K}$ at $p \sim 3 \mathrm{MPa}$ [20]). 
For the same value of $U / w_{0}$ metal-to-insulator transition occurs at $T \approx 940 \mathrm{~K}$ when $\tau_{1}=\tau_{2}=0$ (neglecting the correlated hopping, the Hubbard model) and at $T=0 \mathrm{~K}$ when $\tau_{1}=\tau_{2}=0.015$. If $U / w_{0}=1.98$ then transition from a metallic state to an insulating state is realized at $T \approx 290 \mathrm{~K}$ for $\tau_{1}=\tau_{2}=0$; at $T=0 \mathrm{~K}$ when $\tau_{1}=\tau_{2}=0.005$. Note that at $U \sim 2 w$ the temperatures of metal-to-insulator transition found in both models are essentially different; with a deviation from this ratio the difference decreases.

The obtained temperature dependence of energy gap can explain observable transition from the state of a paramagnetic metal to the paramagnetic Mott-Hubbard insulator state in the $\left(\mathrm{V}_{1-x} \mathrm{Cr}_{x}\right)_{2} \mathrm{O}_{3}$ compound $[17,18]$ in $\mathrm{NiS}_{2}[20]$ and in the $\mathrm{NiS}_{2-x} \mathrm{Se}_{x}$ system [20-22] with the increase of temperature.

To conclude, metal-to-insulator transition observable in the materials with narrow energy bands can be explained based on the proposed approach at realistic values of the parameters characterizing non-equivalence of the Hubbard subbands. This way, the results obtained are essentially distinct from those obtained without taking into account this non-equivalence (the Hubbard model). In particular, the temperature of metal-to-insulator transition is essentially smaller than in the Hubbard model (this fact agrees to the observable transition temperature), and the chemical potential distinguishes from the value $\mu=U / 2$ (obtained in the Hubbard model) and it is temperature dependent.

The authors are grateful to Prof. I. Stasyuk for valuable discussions as well as to the Organizing Committee of the INTAS-Ukraine Workshop on Condensed Matter Physics for grant.

\section{References}

1. Hubbard J. // Proc. Roy. Soc. A, 1963, vol. 276, No. 1365, p. 238-257; Hubbard J. // Proc. Roy. Soc. A, 1964, vol. 281, No. 1386, p. 401-419.

2. Didukh L.D. // Fiz. Tverd. Tela, 1977, vol. 19, p. 1217-1222 (in Russian).

3. Didukh L. Correlation effects in materials with non-equivalent Hubbard subbands. Preprint of Institute for Condensed Matter Physics, ICMP-92-9, Lviv, 1992, p. 32 (in Russian).

4. Didukh L.D. Some properties of materials with narrow energy bands. - In: UkrainianFrench Simposium "Condensed Matter: Science and Industry", Abstracts, Lviv, 1993, p. 275.

5. Didukh L. // Journ. of Phys. Stud., 1997, vol. 1, No. 2, p. 241-250 (in Ukrainian).

6. Hirsh J.E. // Physica B, 1994, vol. 199-200, p. 366.

7. Lin H.Q., Hirsch J.E. // Phys. Rev. B, 1995, vol. 52, No. 22, p. 16155-16164.

8. Amadon J.C., Hirsch J.E. // Phys. Rev. B, 1996, vol. 54, No. 9, p. 6364-6375.

9. Schadschneider A. // Phys. Rev. B, 1995, vol. 51, No. 16, p. 10386-10391.

10. Gagliano E.R., Aligia A.A., Arrachea L., Avignon M. // Phys. Rev. B, 1995, vol. 51, No. 20, p. 14012-14019.

11. Gagliano E.R., Aligia A.A., Arrachea L., Avignon M. // Physica B, 1996, vol. 223-224, No. $1-4$, p. $605-607$. 
12. Arrachea L., Gagliano E.R., Aligia A.A. // Phys. Rev. B, 1997, vol. 55, No. 2, p. 11731184.

13. Santoro G., Manini N., Parola A., Tossatti E. // Phys. Rev. B, 1996, vol. 53, No. 1, p. 828.

14. Chattopadhyay B., Gaitonde D.M. // Phys. Rev. B, 1997, vol. 55, No. 23, p. 1536415367.

15. Izyumov Yu.A. // Usp. Fiz. Nauk., 1995, vol. 165, No. 4, p. 403-427 (in Russian).

16. Gebhard F. The Mott Metal-Insulator Transition - Models and Methods. Berlin, Springer, 1997.

17. Mott N.F. Metal-Insulator Transitions. London, Taylor \& Francis, 1990.

18. Mc Whan D.B., Remeika J.P. Metal-insulator transition in metaloxides. // Phys. Rev. B, 1970, vol. 2, p. 3734-3739.

19. Matsuura A.Y., Shen Z.-X., Dessau D.S., Park C.-H., Thio T., Bennett J.W., Jepsen O. // Phys. Rev. B, 1996, vol. 53, No. 12, p. R7584-R7587.

20. Wilson J.A. The Metallic and Nonmetallic States of Matter. London, Taylor \& Francis, 1985.

21. Yao X., Honig J.M., Hogan T., Kannewurf C., Spalek J. // Phys. Rev. B, 1996, vol. 54, No. 24, p. 17469-17475.

22. Yao X., Kuo Y.-K., Powell D.K., Brill J.W., Honig J.M. // Phys. Rev. B, 1997, vol. 56, No. 12, p. 7129-7135.

23. Didukh L. // Phys. Stat. Sol. b, 1998, vol. 206, p. R5-R6.

24. Didukh L., Hankevych V., Dovhopyaty Yu. Metal-insulator transition in a narrowband model with non-equivalent Hubbard subbands. Preprint of the Institute for Condensed Matter Physics, ICMP-97-26U, Lviv, 1997, p. 18 (in Ukrainian).

\section{Температурно-індукований перехід метал-діелектрик у вузькозонній моделі 3 нееквівалентними габбардівськими підзонами при половинному заповненні}

\section{Л.Дідух, В.Ганкевич}

Тернопільський державний технічний університет ім. І.Пулюя, кафедра фізики, 282001 Тернопіль, вул. Руська, 56

Отримано 8 червня 1998 р., в остаточному вигляді - 22 червня 1998 p.

У цій роботі вивчається температурно-індукований перехід металдіелектрик у вузькозонній моделі з нееквівалентними габбардівськими підзонами при половинному заповненні. Показано, що результати, отримані у розглядуваній моделі, суттєво відрізняються від результатів моделі Габбарда.

Ключові слова: вузькі зони провідності, перехід метал-діелектрик, нееквівалентні габбардівські підзони

PACS: $71.30 .+h, 71.28 .+d, 71.10 . F d, 71.27 .+a$ 